ASTHMA

\title{
Use of inhaled corticosteroids during the first trimester of pregnancy and the risk of congenital malformations among women with asthma
}

\author{
Lucie Blais, Marie-France Beauchesne, Évelyne Rey, Jean-Luc Malo, Amélie Forget
}

Thorax 2007;62:320-328. doi: 10.1136/thx.2006.062950

See end of article for authors' affiliations

Correspondence to: Professeur agrégé L Blais, Université de Montréal, Faculté de pharmacie, $C P$ 6128 , succursale Centreville, Montréal, Québec, Canada H3C 3J7; lucie. blais@umontreal.ca

Received 27 March 2006 Accepted 17 October 2006

\begin{abstract}
Aim: To investigate whether the maternal use of different doses of inhaled corticosteroids (ICSs) during the first trimester of pregnancy for the treatment of asthma increases the risk of congenital malformations in the offspring. Methods: From the linkage of three administrative Canadian databases, a cohort of 4561 pregnancies from women with asthma who delivered between 1990 and 2000 was reconstructed. A two-stage sampling cohort design was used to acquire additional data from the woman's medical chart. Cases of congenital malformation were identified from the medical services database or the hospital database. Using refill patterns of medications, the average daily dose of ICSs used during the first trimester was calculated and categorised as follows: 0, 1-500, 500-1000 and >1000 $\mu \mathrm{g}$ /day in beclomethasone-chlorofluorocarbon equivalent. A Generalized Estimation Equation model was used to estimate the adjusted odds ratio of congenital malformation as a function of ICS daily dose. All analyses were performed for all malformations and major malformations separately.

Results: Within the cohort 418 babies were identified with a congenital malformation (9.2\%), 278 of which had a major malformation. About $40 \%$ of women used ICSs during the first trimester, but only $5.3 \%$ of women used $>500 \mu \mathrm{g} /$ day. The adjusted odds ratio $(95 \% \mathrm{Cl})$ for all malformations associated with the use of ICSs during the first trimester was: $0.77(0.53$ to 1.13$)$ for $1-500,0.41(0.19$ to 0.92$)$ for $501-1000$ and 1.00 $(0.42$ to 2.36$)$ for $>1000 \mu \mathrm{g} /$ day. The corresponding figures for major malformations were 0.9010 .64 to $1.24), 0.56$ (0.22 to 1.43 ) and 1.67 (0.56 to 5.03 ).

Conclusion: This study adds evidence to the safety of ICSs for the treatment of asthma during pregnancy, with regard to the likelihood of congenital malformation.
\end{abstract}

A sthma is one of the most prevalent chronic diseases for which a pharmacological treatment might be necessary during pregnancy, with $4-7 \%$ of women taking medications for asthma during pregnancy. ${ }^{1-3}$ From the recommendations of the Working Group on Asthma and Pregnancy, asthma should be treated during pregnancy as aggressively as other times in order to keep it under control. ${ }^{4}$ Inhaled corticosteroids (ICS), which are the cornerstone treatment in asthma, are thus recommended during pregnancy at doses similar to the ones recommended in the international guidelines for the treatment of asthma. ${ }^{4}$

Despite clear recommendations for the treatment of asthma during pregnancy, fears of congenital malformations due to maternal intake of ICS during the first trimester are still present. These fears might be attributed, at least in part, to the increased risk of congenital malformations found among women who took oral corticosteroids during pregnancy. ${ }^{5-7}$ There are five investigative studies on the relationship between the intake of ICS and the risk of congenital malformations. ${ }^{8-12}$ These five studies reported no increased risk of congenital malformations with ICS intake during pregnancy, but none of them considered dosing of ICS and four of them were impeded by low statistical power. ${ }^{9-12}$ With a larger sample size, the Swedish study compared infants of mothers with asthma who used ICS during their first trimester with all infants in the Swedish Medical Birth Registry. ${ }^{8}$ However, the results from this study should be interpreted with caution since mothers with asthma were compared with mothers without asthma in an analysis that did not adjust for the control of asthma, the use of other medications for asthma and the use of teratogenic medications during pregnancy. ${ }^{8}$
We performed a large population-based cohort study to investigate the association between the intake of various dosage ranges of ICS among women with asthma during the first trimester of pregnancy and the risk of congenital malformations, while adjusting for several confounding variables.

\section{METHODS}

\section{Source of data}

Data for this study were retrieved from three administrative databases from the Canadian province of Québec and from the medical chart of mothers. The database of the "Régie de l'assurance-maladie du Québec" (RAMQ) provides information on medical services dispensed to all residents of Québec and prescribed medications filled in community pharmacies for residents insured by the RAMQ for their medications. These include the elderly, recipients of social welfare since 1980 and since January 1997, 1.7 million other adherents, mainly workers and their families who are not covered under a private drug insurance plan at their workplace, which represent about $43 \%$ of the residents of the province. ${ }^{13}$ MED-ECHO contains information on all hospitalisations occurring in the province and the "Fichier des événements démographiques", administered by the "Institut de la statistique du Québec (ISQ)", provides information on all births and stillbirths. The RAMQ and MED-ECHO databases have often been used in the past for epidemiological research in the field of asthma leading to scientific articles published in renowned medical journals. ${ }^{14}{ }^{15}$

Abbreviations: CFC, chlorofluorocarbon; GEE, Generalized Estimation Equation; ICS, inhaled corticosteroid; ISQ, Institut de la statistique du Québec; RAMQ, Régie de l'assurance-maladie du Québec 
Data recorded in the RAMQ prescription database have been formally evaluated and found to be comprehensive and valid, ${ }^{16}$ as were some medical diagnoses recorded in the MED-ECHO database ${ }^{17}$ and the medical diagnosis for asthma recorded in the RAMQ Medical Services database. ${ }^{18}$ Important confounding variables such as family history of congenital malformations and maternal life style habits during pregnancy are not included in the administrative databases and thus were retrieved from the mother's medical chart in which they are routinely recorded during prenatal visits.

An authorisation was obtained from the "Commission d'accès à l'information du Québec" before requesting and linking the information from the RAMQ, MED-ÉCHO, the ISQ and medical charts. This research project was approved by the ethics committees of Hôpital du Sacré-Coeur de Montréal and Hôpital Ste-Justine (Montréal, Québec, Canada).

\section{Study design}

The design was a two-stage sampling cohort study. ${ }^{19}{ }^{20}$ In this design, a cohort is first formed (first stage of sampling) and the outcome and the primary exposure have to be known for all patients included in the cohort. From this cohort, a sample of patients is selected (second stage of sampling) based on their outcome and exposure status and, for this sample of patients, supplementary data are obtained on confounding variables. In our study, the first stage of sampling consisted of a cohort of pregnancies from women with asthma and their children formed from the linkage of the RAMQ, MED-ECHO and ISQ databases, whereas the second stage of sampling consisted of a sample of pregnancies from the cohort for which the medical chart of the mother was retrieved. The choice of the pregnancy as the unit of analysis allowed us to take into account the fact that a woman could have more than one pregnancy during the study period, as well as the social, asthmatic, and the medical conditions of the mother, which may vary from one pregnancy to another.

The cohort was first selected from the RAMQ database, and the inclusion criteria were: (1) having at least one pregnancy ending in a delivery (live births and still births) between 1990 and 2000; (2) aged 12-44 years at the beginning of the pregnancy; (3) having at least one diagnosis of asthma (ICD9 code: 493) and at least one prescription for an asthma medication at any point of time in the previous 2 years or during pregnancy and (4) being covered by the RAMQ drug insurance plan for at least 1 year before and throughout the duration of the pregnancy. The cohort was linked with the MED-ECHO and "Fichier des événements démographiques" databases, and each woman was then matched with her children.

For each pregnancy included in the cohort we obtained from the RAMQ, for the mothers and the newborns, data on all prescriptions filled such as date of filling, name, dose, dosage form, quantity and duration of the prescription, encrypted identification and specialty of the prescribing physicianinpatient and ambulatory medical services dispensed-nature of the medical act, date, site of medical practice (outpatient clinic, emergency department, hospitalisation), diagnosis code, encrypted identification and specialty of the treating physician in the year preceding, during and l year after pregnancy. The RAMQ also provided data associated with the date of birth of the mothers and children, whether the mother was receiving social assistance and the area of residence of the mother during her pregnancy. MED-ECHO provided data on all maternal acute care hospitalisations, including principal diagnosis, up to 15 secondary diagnoses, date of admission and length of hospitalisation, occurring for the year preceding and during pregnancy, in addition to the length of gestation and birth weight from the delivery hospitalisation. With respect to the children, we received hospitalisation data for the first year of life. The "Fichier des événements démographiques" provided data relevant to the level of education of the mother and the parity of the ongoing pregnancy.

Using the gestational age and date of birth of the offspring recorded in MED-ECHO and RAMQ databases, we retrospectively identified the date of the first day of the last menstrual period to define the calendar date of the beginning and the calendar date of the end of each pregnancy in the cohort, first stage of sampling. We also assessed the outcome, which is congenital malformation and ICS exposure during the first trimester for each pregnancy in the cohort.

For the second stage of sampling, we selected from the cohort all cases of congenital malformation and we selected two nonmalformed babies per case, matched on the use of ICS during the first trimester of pregnancy and delivery hospital. For all pregnancies selected at this stage, the RAMQ provided us with the medical insurance number of the mother and the name of the hospital in which she gave birth. Two trained research nurses went to all hospitals to identify and retrieve information on confounding variables from the mother's medical chart. These variables are routinely recorded using a standardised form during prenatal visits. A computerised data collection tool was provided to the research nurses and the required information was captured directly on the computer.

\section{Congenital malformations}

All cases of congenital malformation were identified within the cohort using ICD-9 diagnosis codes specific to congenital malformations (ICD-9: 152, 155, 186, 188, 190-192, 197-198, 204-205, 237, 740-759, 778) obtained from the RAMQ and MED-ECHO databases, either from the mother's or the infant's records. Our list of congenital malformations was compared with the list provided by the Collaborative Perinatal Group ${ }^{21}$ and verified by a geneticist from the Montreal's Hôpital SteJustine for exactness and completeness. An infant was identified as a case if he/she had at least one diagnosis of congenital malformation at birth or during the first year of life recorded in RAMQ or MED-ECHO databases.

The geneticist also classified the malformations as either minor or major. A congenital malformation was classified as major if it could be life threatening or cause major cosmetic defects and if there was at least one hospitalisation related to the malformation during the first year of life.

\section{Exposure to ICS}

For each pregnancy included in the cohort (first stage of sampling), we assessed the exposure to ICS (beclomethasone, fluticasone, budesonide, flunisolide and triamcinolone) during the first 12 weeks of gestation. Using the medication's name, dose, dosage form, quantity and the date of filling provided by the RAMQ database, we developed an algorithm to estimate the maternal consumption of ICS during the first trimester by looking at prescription renewals and length of time between renewals. Using the equivalency table published in the Canadian Asthma Consensus report, we converted the mean daily dose of ICS into beclomethasone-chlorofluorocarbon (CFC) equivalents. ${ }^{22}$ The details of the algorithm can be obtained from the authors on request. The mean daily dose of ICS was then divided into four categories: $0 \mu \mathrm{g},>0-500 \mu \mathrm{g}$, $>500-1000 \mu \mathrm{g}$ and $>1000 \mu \mathrm{g}$ beclomethasone-CFC equivalent.

\section{Confounding variables}

Five categories of variables including maternal sociodemographic characteristics, maternal chronic conditions, pregnancy-related variables, asthma-related variables and 
maternal life style habits during pregnancy were considered as potential confounding variables. Sociodemographic characteristics of the mother included age at the beginning of pregnancy (12-18, 19-34, 35-44 years), receipt of social assistance during pregnancy (yes/no), area of residence (rural/urban) during pregnancy and the level of education $(\leqslant 12, \geqslant 13$, missing). Maternal chronic conditions included diabetes mellitus (yes/ no), epilepsy (yes/no), thyroid disorder (yes/no) and use of recognised teratogenic medications during the first trimester of pregnancy (yes/no). ${ }^{23}$ Diabetes mellitus and epilepsy were identified from either diagnoses or filled prescriptions of related medications 1 year before or during pregnancy using a specific algorithm that we developed for each condition, details of which are available on request. Pregnancy-related variables included parity (first/second or more), multiple pregnancy (singleton/twins or more), medically induced abortions before the current pregnancy (yes/no) and family history of congenital malformations (yes/no). Asthma-related variables included the use of intranasal corticosteroids during the first trimester of pregnancy (yes/no), the use of ICS in the year preceding the pregnancy (yes/no), as well as the use of oral corticosteroids (yes/no), inhaled or oral short-acting $\beta_{2}$-agonists $(0,>0-3,>3-$ $10,>10$ doses per week), inhaled or oral long-acting $\beta_{2^{-}}$ agonists (yes/no), oral theophylline (yes/no), emergency department visits or hospitalisations for asthma (yes/no) in the year preceding and during the first trimester of pregnancy. These parameters were used as markers of the control of asthma. Life style habits during pregnancy (retrieved from the mother's medical chart) included cigarette smoking (0, 1-20, $\geqslant 21$ cigarettes per day), alcohol use (yes/no), illicit drug use (yes/no), intake of multivitamins (yes/no), intake of folic acid (yes/no) and exposure to irradiations or $x$ rays (yes/no).

\section{Statistical analysis}

We first estimated the overall crude prevalence of all congenital malformations and major malformations in the cohort, separately. We also estimated the crude prevalence of all congenital malformations and major malformations for each dosing range of ICS taken during the first trimester of pregnancy, and for all confounding variables, separately.

The association between the dose of ICS taken during the first trimester and the risk of all congenital malformations was investigated with Generalized Estimation Equation (GEE) models. These regression models can model the effect of independent variables (including the main exposure and confounding variables) on several types of outcomes (dichotomous, continuous, count). These models can also take into account the fact that a woman could contribute two or more pregnancies to the analysis by estimating the correlation between consecutive pregnancies. In our analysis, the outcome was dichotomous (presence or absence of a congenital malformation) and the GEE model was based on a logistic regression model (ie, logit function) to estimate the effect of ICS exposure and confounding variables on the odds of having a congenital malformation. ${ }^{24}$ A first model was built using confounding variables measured for all pregnancies in the cohort at the first stage of sampling-variables retrieved from the administrative databases. A second model was then built among pregnancies selected at the second stage of sampling using all potential confounding variables, including those retrieved from the mother's medical chart. For both models, a backward selection procedure was used to select the most parsimonious model. ${ }^{25}$ Adjusted odds ratios (OR) and their 95\% CIs were estimated.

The final estimate of the adjusted OR for congenital malformations associated with each dosing range of ICS compared with no use of ICS was found by applying the second stage sampling fractions to the estimates found at the second stage of sampling following the method developed by Collet et al. ${ }^{19}$

Using the same analytical strategy, we investigated the association between major congenital malformations and the dose of ICS taken during the first trimester of pregnancy.

\section{RESULTS}

At the first stage of sampling, the cohort was formed of 3505 mothers who had a total of 4561 pregnancies ending with a live birth or a stillbirth between 1990 and 2000. In all, 75\% of the women had only one pregnancy during the study period, with an average of 1.3 pregnancies per woman.

Within this cohort we identified 418 babies with at least one congenital malformation, cardiac malformations being the most prevalent followed by musculoskeletal malformations (table 1). Among those 418 babies, 278 had a major malformation. The crude prevalences of any congenital malformation and major congenital malformations detected at birth or during the first year of life were $9.2 \%$ (8.3\% to $10.0 \%$ ) and $6.1 \%$ (5.4\% to $6.8 \%)$, respectively.

At the second stage of sampling we were able to retrieve the maternal medical chart for 361 of the 418 cases of congenital

Table 1 Distribution of congenital malformations

\begin{tabular}{|c|c|c|c|c|}
\hline & \multicolumn{2}{|c|}{ All malformations } & \multicolumn{2}{|c|}{ Major malformations } \\
\hline & $\mathbf{n}$ & $\%$ & $\mathbf{n}$ & $\%$ \\
\hline Cardiac & 135 & 21.16 & 135 & 28.07 \\
\hline Musculoskeletal & 115 & 18.03 & 58 & 12.06 \\
\hline Genital organs & 51 & 7.99 & 26 & 5.41 \\
\hline Digestive system & 45 & 7.05 & 37 & 7.69 \\
\hline Eye, ear, face and neck & 43 & 6.74 & 30 & 6.24 \\
\hline Circulatory system & 36 & 5.64 & 32 & 6.65 \\
\hline Cleft palate and cleft lip & 31 & 4.86 & 31 & 6.44 \\
\hline Nervous system & 30 & 4.70 & 30 & 6.24 \\
\hline Urinary system & 29 & 4.55 & 29 & 6.03 \\
\hline Limbs & 20 & 3.13 & 5 & 1.04 \\
\hline Respiratory system & 15 & 2.35 & 8 & 1.66 \\
\hline Spina bifida & 15 & 2.35 & 15 & 3.12 \\
\hline Integument & 11 & 1.72 & 9 & 1.87 \\
\hline Chromosomal & 4 & 0.63 & 4 & 0.83 \\
\hline Other & 58 & 9.09 & 32 & 6.65 \\
\hline Total $^{*}$ & 638 & 100 & 481 & 100 \\
\hline
\end{tabular}


malformation (86.4\%) and for 728 of the 836 selected controls $(87.1 \%)$.

Tables $2 \mathrm{a}$ and $2 \mathrm{~b}$ show the characteristics of the women included in the cohort (ie, at the first stage of sampling). In these tables the unit of analysis is the pregnancy since $25 \%$ of the women contributed to more than one pregnancy in the analysis. Most of the women were aged between 19 and 34 years, received social assistance, had $\leqslant 12$ years of education, lived in an urban area, were primigravida, had a single pregnancy, were free of diabetes and epilepsy and did not use teratogenic drugs during the first trimester (table 2a). In terms of ICS treatment, $47.2 \%$ of the women used it before pregnancy whereas only $40.0 \%$ used it during the first trimester (table $2 \mathrm{~b}$ ). Among users, the average daily dose of ICS taken during the first trimester was $231 \mu \mathrm{g}$ in beclomethasone-CFC equivalent ( $124.9 \mu \mathrm{g} /$ day in the $0-500 \mu \mathrm{g}$ category; $686.7 \mu \mathrm{g} /$ day in the $500-1000 \mu \mathrm{g}$ category and $1508.1 \mu \mathrm{g} /$ day in the $>1000 \mu \mathrm{g}$ category), and only $5.3 \%$ of the women took a daily dose of more than $500 \mu \mathrm{g}$. In all, $63 \%$ of ICS prescriptions used during the first trimester were for beclomethasone, $19 \%$ for fluticasone and $17 \%$ for budesonide. We also observed that a nonnegligible proportion of women had uncontrolled asthma. In fact, in the year preceding the pregnancy, $12.7 \%$ of the women filled at least one prescription for oral corticosteroids, $38.2 \%$ took more than three doses of inhaled or oral short-acting $\beta_{2^{-}}$ agonists per week on average, and $13.4 \%$ had at least one emergency department visit or one hospitalisation for asthma. The corresponding figures were $4.8 \%, 35.0 \%$ and $6.2 \%$ during the first trimester of pregnancy.

Tables $2 \mathrm{a}$ and $2 \mathrm{~b}$ also present the crude rates for all congenital malformations and major congenital malformations as a function of each covariable. In table $2 \mathrm{a}$, we observe that women with asthma having higher levels of education, living in a rural area, and free of epilepsy and diabetes mellitus tended to be less likely to have a baby with a congenital malformation (all malformations and major malformations). In table $2 \mathrm{~b}$, we observe that women who took moderate doses of ICS (500$1000 \mu \mathrm{g} /$ day) during the first trimester of pregnancy were less likely than non-users to have a baby with a congenital malformation, whereas women who took $>1000 \mu \mathrm{g}$ per day were more likely (all malformations and major malformations). We also observed that women with markers of uncontrolled asthma during the first trimester of pregnancy tended to be more likely to have a baby with a congenital malformation (all malformations and major malformations).

Table 3 presents the maternal characteristics for women selected at the second stage of sampling. In this sample, $>50 \%$ of the mothers reported smoking cigarettes during pregnancy and there were slightly more smokers among women using ICS than among non-users. This high prevalence of cigarette smoking might be explained, at least in part, by the high proportion of women with low socioeconomic status in our cohort. Few mothers reported drinking alcohol or using illicit drugs during pregnancy, while around 30\% reported taking multivitamins. Close to $13 \%$ of women who had a baby with a congenital malformation and 6-9\% of the other women had a family history of congenital malformations before the current pregnancy. The prevalence of thyroid disorder, exposure to irradiations and medically induced abortions was low and did not differ between users and non-users of ICS.

In table 4 we present the results of the GEE models in which we investigated the association between the dose range of ICS taken during the first trimester of pregnancy and the risk of all congenital malformations in the offspring. We first present the results of the GEE model that was built based on the 4561 pregnancies selected at the first stage of sampling. The dose of ICS was forced in the model and the covariables were kept in the model only if they were found to act as a confounder of the ICS/malformation association or if they were significantly associated with the risk of congenital malformations. This model showed that mothers with asthma using a low dose of ICS tended to be less likely to have a baby with a congenital malformation than non-users (adjusted OR (95\% CI) $0.76(0.56$ to 1.05$)$ ), that users of moderate doses were significantly (61\%) less likely to have a baby with a congenital malformation than non-users (adjusted OR (95\% CI) 0.39 (0.19 to 0.82), whereas users of high doses of ICS were found to have almost the same risk of congenital malformations as non-users.

From this model, we also found that women who had an emergency department visit or a hospitalisation for asthma during the first trimester tended to be more likely to have a baby with a congenital malformation. However, the observed association did not reach statistical significance. On the other hand, the use of inhaled or oral long-acting $\beta_{2}$-agonists before pregnancy was associated with an increased risk of congenital malformations (OR 2.83; 95\% CI 1.34 to 5.97). In addition, woman who had a multiple pregnancy and those who had epilepsy were found to be more at risk of having a baby with a congenital malformation. We also found that women with $\geqslant 13$ years of education were at $50 \%$ less risk (OR $0.50 ; 95 \%$ CI 0.29 to 0.87 ) and women living in a rural area were at $27 \%$ less risk (OR $0.73 ; 95 \%$ CI 0.55 to 0.97 ) of having a baby with a congenital malformation.

The results of the final model integrating the two stages of sampling are also presented in table 4. For ICS exposure during the first trimester of pregnancy, we found in this final model almost the same results as in the first-stage sampling modelthat is, a moderate dose of ICS taken during the first trimester reduced the risk of congenital malformations (adjusted OR $0.41 ; 95 \%$ CI 0.19 to 0.92 ), whereas low and high doses taken during the same period were not found to be significantly associated with an increased risk of congenital malformation. The adjusted ORs for the covariables found in this model were similar to those found in the first-stage model. However, and with respect to this model, we found that in addition to multiple pregnancy and epilepsy, women with a thyroid disorder (adjusted OR 1.95; 95\% CI 1.05 to 3.64) and women who had a family history of congenital malformation (adjusted OR $1.75 ; 95 \%$ CI 1.14 to 2.69 ) were found to be at increased risk of having a baby with a congenital malformation.

Similar results were obtained for the association between the dose of ICS and major congenital malformations (table 5). However, in this analysis we observed a trend towards an increased risk of major congenital malformation associated with the use of $>1000 \mu \mathrm{g}$ ICS per day (OR 1.67), but this OR was not statistically significant.

\section{DISCUSSION}

In this study, we found that ICS intake during the first trimester of pregnancy, regardless of the dosing range under study, was not significantly associated with an increase in the risk of all congenital malformations and major congenital malformations in the offspring of mothers with asthma. Indeed, we found that moderate doses of ICS taken during the first trimester were significantly associated with a $59 \%$ reduction in the risk of all congenital malformations compared with no ICS.

The results of this study are consistent with the results found in other studies investigating the safety of ICS during pregnancy. ${ }^{8-12}$ Schatz et al (two studies), Greenberger et al and Silverman et al found no increased risk of congenital malformations in association with ICS use, but these four studies were under powered..$^{9-12}$ Schatz and colleagues studied the risk of major congenital malformations associated with the 
Table 2 Characteristics of the women included in the cohort at the first stage of sampling: (A) Demographic and pregnancy characteristics. (B) Asthma-related variables

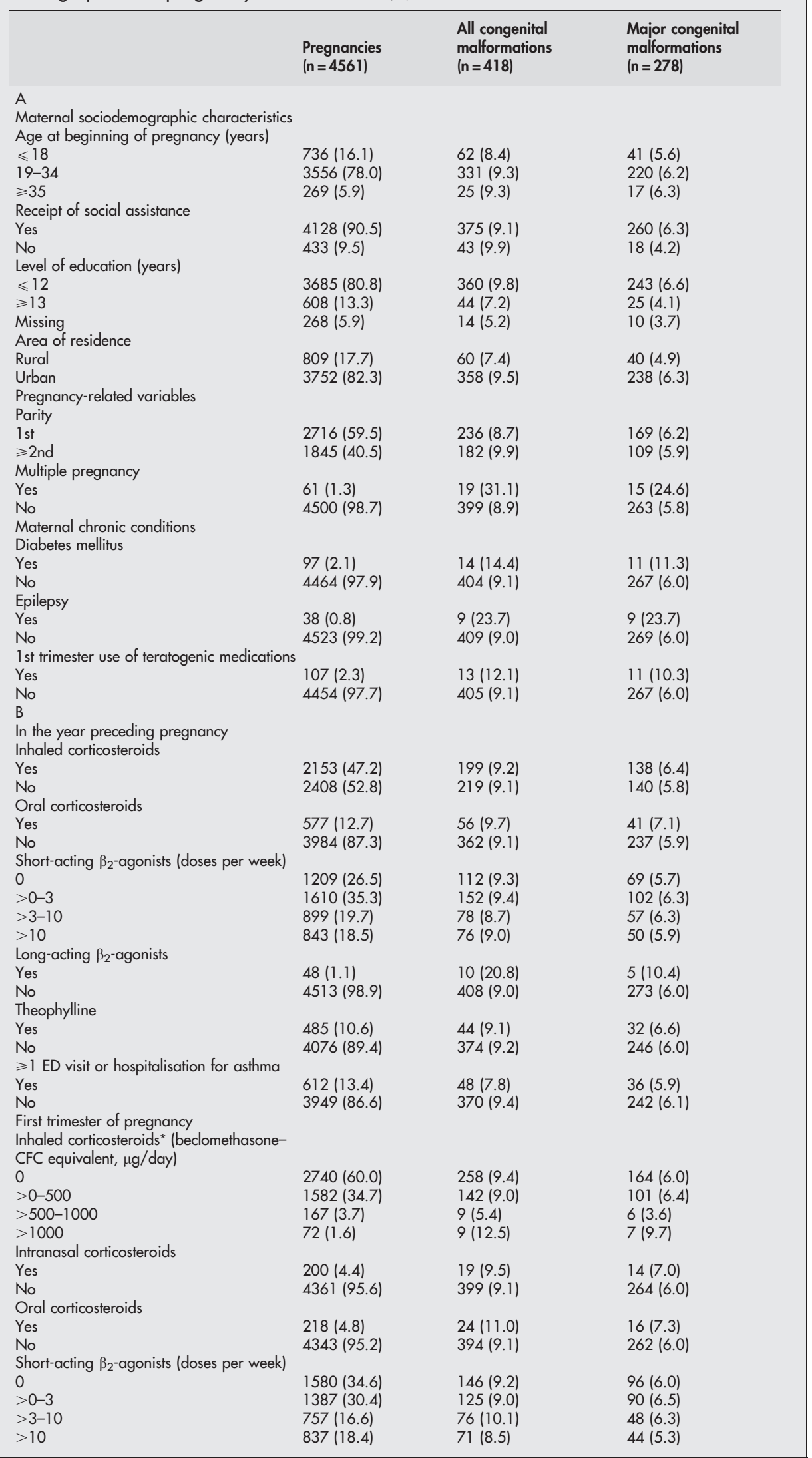




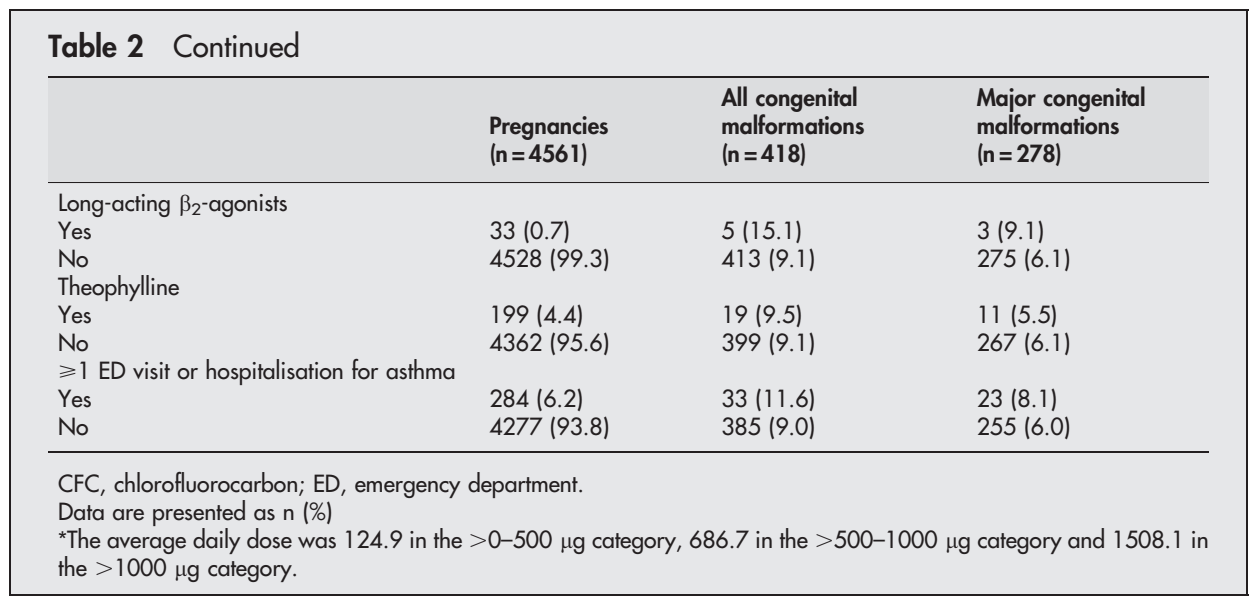

use of ICS in two studies. In the first published study, 824 pregnant women with asthma and 678 women without asthma were recruited and 147 were exposed to ICS at some point during pregnancy. ${ }^{9}$ They found that women who used inhaled or intranasal corticosteroids were less likely to have a baby with a congenital malformation than non-users, including women with and without asthma, but the observed difference did not reach statistical significance ( $4.9 \%$ vs $5.4 \%$ ). The second study was based on 2123 pregnant women with asthma of whom 722 were exposed to ICS at some point during pregnancy. ${ }^{11}$ They found no statistically significant difference in the risk of major congenital malformations between women exposed and unexposed to ICS ( $1.9 \%$ vs 2.0$)$. This study had a power of $27 \%$ to detect a 50\% increase in congenital malformations among women exposed to ICS during pregnancy. Greenberger and colleagues ${ }^{10}$ studied the safety of beclomethasone-CFC during pregnancy to treat severe asthma among 43 pregnancies and found only one case of congenital malformation, which was close to the expected number of cases. Silverman and colleagues $^{12}$ performed a subgroup analysis of 319 pregnancies that were reported in a randomised-controlled trial testing the early use of ICS among mild-to-moderate persistent asthma. They found no significant difference in the risk of congenital malformations between women exposed to ICS (400 $\mu \mathrm{g} / \mathrm{day}$ of budesonide) during pregnancy compared with placebo (2\% vs $3 \%)$. Källen and colleagues ${ }^{8}$, in a much broader study based on

Table 3 Characterictics of women selected at the second stage of sampling $(n=1089)$

\begin{tabular}{|c|c|c|c|c|}
\hline & \multirow{2}{*}{$\begin{array}{l}\text { All congenital } \\
\text { malformations } \\
(n=361)\end{array}$} & \multirow{2}{*}{$\begin{array}{l}\text { Major congenital } \\
\text { malformations } \\
(\mathrm{n}=244)\end{array}$} & \multicolumn{2}{|c|}{$\begin{array}{l}\text { Pregnancies non-malformed } \\
\text { babies }(n=728)\end{array}$} \\
\hline & & & No ICS $(n=451)$ & $I^{\prime C S}(n=277)$ \\
\hline \multicolumn{5}{|c|}{$\begin{array}{l}\text { Cigarette smoking (number per } \\
\text { day) }\end{array}$} \\
\hline 0 & $155(42.9)$ & $104(42.6)$ & $205(45.5)$ & $144(52.0)$ \\
\hline $1-20$ & $165(45.7)$ & $108(44.3)$ & $185(41.0)$ & $96(34.7)$ \\
\hline$\geqslant 21$ & 41 (11.4) & $32(13.1)$ & $61(13.5)$ & 37 (13.3) \\
\hline \multicolumn{5}{|c|}{ Alcohol use } \\
\hline Yes & $5(1.4)$ & $4(1.6)$ & $11(2.4)$ & $6(2.2)$ \\
\hline No & $356(98.6)$ & $240(98.4)$ & $440(97.6)$ & 271 (97.8) \\
\hline \multicolumn{5}{|c|}{ Illicit drug use } \\
\hline Yes & $16(4.4)$ & $8(3.3)$ & $31(6.8)$ & $14(5.1)$ \\
\hline No & $345(95.6)$ & $236(96.7)$ & $420(93.1)$ & $263(94.9)$ \\
\hline \multicolumn{5}{|c|}{ Intake of multivitamins } \\
\hline Yes & $116(32.1)$ & $75(30.7)$ & 157 (34.8) & $91(32.9)$ \\
\hline No & $245(67.9)$ & $169(69.3)$ & $294(65.2)$ & $186(67.1)$ \\
\hline \multicolumn{5}{|c|}{ Intake of folic acid } \\
\hline Yes & $11(3.0)$ & $6(2.5)$ & $6(1.3)$ & $8(2.9)$ \\
\hline \multirow{2}{*}{\multicolumn{5}{|c|}{$\begin{array}{l}\text { Family history of congenital } \\
\text { malformation }\end{array}$}} \\
\hline & & & & \\
\hline Yes & $46(12.7)$ & $34(13.9)$ & $30(6.7)$ & $25(9.0)$ \\
\hline No & $315(87.3)$ & $210(86.1)$ & 421 (93.3) & $252(91.0)$ \\
\hline \multicolumn{5}{|c|}{ Thyroid disorder } \\
\hline Yes & $20(5.5)$ & $16(6.6)$ & $12(2.7)$ & $13(4.7)$ \\
\hline No & 341 (94.5) & $228(93.4)$ & 439 (97.3) & $264(95.3)$ \\
\hline \multicolumn{5}{|c|}{ Irradiations or $x$ rays } \\
\hline Yes & $12(3.3)$ & $8(3.3)$ & $11(2.4)$ & $12(4.3)$ \\
\hline No & $349(96.7)$ & $236(96.7)$ & $440(97.6)$ & $265(95.7)$ \\
\hline \multicolumn{5}{|c|}{$\begin{array}{l}\text { Medically induced abortion before } \\
\text { the current pregnancy }\end{array}$} \\
\hline Yes & $10(2.7)$ & $7(2.9)$ & $10(2.2)$ & $5(1.8)$ \\
\hline No & 351 (97.3) & $237(97.1)$ & $441(97.8)$ & 272 (98.2) \\
\hline
\end{tabular}


Table 4 Adjusted odds ratio of any congenital malformation associated with the use of inhaled corticosteroids during the first trimester of pregnancy

\begin{tabular}{|c|c|c|c|}
\hline & \multicolumn{2}{|c|}{ First stage sampling $(n=4561)$} & \multirow{2}{*}{$\begin{array}{l}\text { Final estimates* }(n=1089) \\
\text { Adjusted OR }(95 \% \mathrm{Cl})\end{array}$} \\
\hline & Crude OR & Adjusted OR (95\% Cl) & \\
\hline \multicolumn{4}{|l|}{ During lst trimester } \\
\hline \multicolumn{4}{|l|}{ Use of ICS ( $\mu \mathrm{g} /$ day) } \\
\hline 0 & Reference & & Reference \\
\hline$>0-500$ & 0.95 & $0.76(0.56$ to 1.05$)$ & $0.77(0.53$ to 1.13$)$ \\
\hline$>500-1000$ & 0.55 & 0.39 (0.19 to 0.82 ) & $0.41(0.19$ to 0.92$)$ \\
\hline$>1000$ & 1.37 & 0.92 (0.42 to 2.03 ) & $1.00(0.42$ to 2.36$)$ \\
\hline Oral corticosteroids (yes/no) & 1.24 & NRT & $1.93(0.94$ to 3.98$)$ \\
\hline $\begin{array}{l}\text { ED visit or hospitalisation for asthma } \\
\text { (yes/no) }\end{array}$ & 1.33 & $1.43(0.96$ to 2.14$)$ & NRt \\
\hline \multicolumn{4}{|l|}{ Before pregnancy } \\
\hline Use of ICS (yes/no) & 1.02 & $1.19(0.89$ to 1.60$)$ & $1.13(0.76$ to 1.66$)$ \\
\hline Use of long-acting $\beta_{2}$-agonists (yes/no) & 2.65 & $2.83(1.34$ to 5.97$)$ & NRt \\
\hline \multicolumn{4}{|l|}{ Maternal characteristics } \\
\hline \multicolumn{4}{|l|}{ Level of education } \\
\hline$\leqslant 12$ & Reference & & Reference \\
\hline$\geqslant 13$ & 0.51 & 0.50 (0.29 to 0.87$)$ & $0.48(0.25$ to 0.92$)$ \\
\hline Missing & 0.72 & $0.72(0.52$ to 0.99$)$ & $0.71(0.47$ to 1.06$)$ \\
\hline Area of residence (rural/urban) & 0.76 & 0.73 (0.55 to 0.97$)$ & NRt \\
\hline Multiple pregnancy (yes/no) & 4.65 & $4.94(2.82$ to 8.66$)$ & 7.17 (2.57 to 20.01$)$ \\
\hline Epilepsy (yes/no) & 3.12 & 3.21 (1.49 to 6.91 ) & 6.06 (1.59 to 23.09$)$ \\
\hline Thyroid disorder (yes/no) & \multicolumn{2}{|c|}{ Not availableł } & 1.95 (1.05 to 3.64$)$ \\
\hline $\begin{array}{l}\text { Family history of congenital malformations } \\
\text { (yes/no) }\end{array}$ & \multicolumn{2}{|l|}{ Not availableł } & $1.75(1.14$ to 2.69$)$ \\
\hline $\begin{array}{l}\text { ED, emergency department; ICS, inhaled cort } \\
\text { "Estimates were based on the first and secon } \\
\text { TNR, not retained in the model. } \\
\text { †These variables were not available in the adn }\end{array}$ & $\begin{array}{l}\text { steroids. } \\
\text { tage of sampling }\end{array}$ & 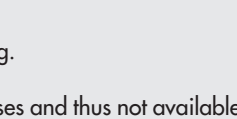 & 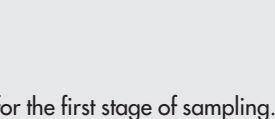 \\
\hline
\end{tabular}

2014 infants of mothers identified through the Swedish Medical Birth Registry who reported the use of budesonide in early pregnancy, found no increase in the rate of congenital malformation among ICS users compared with all infants recorded in the Swedish Medical Birth Registry (3.8\% vs 3.5\%). A major weakness of these studies is the lack of information on the dose of ICS taken during pregnancy.

Uncontrolled and severe asthma has been associated with adverse perinatal outcomes ${ }^{10}{ }^{26-29}$ and it is for this reason that the American guidelines for the treatment of asthma during pregnancy do recommend treatment with ICS to maintain asthma under control. ${ }^{40}$ Uncontrolled asthma is potentially dangerous to the fetus since hypoxia combined with respiratory alkalosis decreases the placental blood flow. ${ }^{31-33}$ Decreased fetal blood oxygen could result in abnormal growth and development of the fetus. ${ }^{31}{ }^{32}{ }^{34}$ Moreover, two retrospective studies have reported an increased risk of congenital malformation among mothers with asthma. In a large database study,
Demessie $e t a l^{35}$ reported a statistically significant increased risk of $37 \%$ of congenital malformations for women with asthma compared with pregnant women without asthma. Bahna and Bjerkedal $^{36}$ also reported an increased risk of congenital malformations when mothers with asthma were compared with mothers without asthma (5.0\% vs 3.9\%), but the observed difference did not reach statistical significance. In addition, in our study we found an increased risk of congenital malformations, more than double, among mothers using longacting $\beta_{2}$-agonists before pregnancy, which was a marker of moderate to severe asthma at the time of the study. However, it is worth noting that prospective studies did not find a statistically significant association between asthma and the risk of congenital malformations. ${ }^{9-12}$

Our study investigated further the association between maternal ICS use during pregnancy and the risk of congenital malformations by taking into account the average daily dose of ICS during the first trimester. Our results showed that women

Table 5 Adjusted odds ratio of major congenital malformations associated with the use of inhaled corticosteroids during the first trimester of pregnancy

\begin{tabular}{|c|c|c|c|}
\hline \multirow[b]{2}{*}{ Use of ICS ( $\mu \mathrm{g} /$ day) } & \multicolumn{2}{|c|}{ First stage sampling* $(n=4421)$} & \multirow{2}{*}{$\begin{array}{l}\text { Final estimates† }(\mathrm{n}=972) \\
\text { Adjusted OR }(95 \% \mathrm{Cl})\end{array}$} \\
\hline & Crude OR & Adjusted OR $(95 \% \mathrm{Cl})$ & \\
\hline 0 & Reference & & \\
\hline$>0-500$ & 1.06 & 0.94 (0.63 to 1.39$)$ & 0.90 (0.64 to 1.24$)$ \\
\hline$>500-1000$ & 0.58 & $0.56(0.22$ to 1.39$)$ & $0.56(0.22$ to 1.43$)$ \\
\hline$>1000$ & 1.68 & $1.92(0.78$ to 4.74$)$ & $1.67(0.56$ to 5.03$)$ \\
\hline
\end{tabular}

ICS, inhaled corticosteroid.

*Estimates were based on the first stage of sampling only and adjusted for the number of doses of short-acting $\beta_{2}$. agonists used in the first trimester of pregnancy, use of ICS before pregnancy, maternal level of education, multiple pregnancy, maternal epilepsy and diabetes mellitus.

tEstimates were based on the first and second stage of sampling and adjusted for the number of doses of short-acting $\beta_{2^{-}}$ agonists used and the use of long-acting inhaled $\beta_{2}$-agonists in the first trimester of pregnancy, use of oral corticosteroids before pregnancy, level of education, multiple pregnancy, maternal epilepsy, maternal thyroid disorder and family history of congenital malformations. 
taking low doses of ICS during the first trimester (124.9 $\mu \mathrm{g}$ of beclomethasone-CFC equivalent per day on average) were associated with a lower risk of all congenital malformation, but the observed 23\% reduction did not reach statistical significance. Our results also showed that women taking moderate doses $(686.7 \mu \mathrm{g}$ of beclomethasone-CFC equivalent per day on average) were found to be $59 \%$ less likely to have a baby with all congenital malformations than non-users. On the other hand, women taking high doses (1508.1 $\mu \mathrm{g}$ of beclomethasone-CFC equivalent per day on average) were found to be as likely as non-users to have a baby with a congenital malformation. These results show that, even at high doses, ICS exposure during pregnancy was not associated with an increased risk of all congenital malformation. However, when we looked at major congenital malformations separately, we found a tendency towards an increased risk associated with the use of more than $1000 \mu \mathrm{g}$ ICS per day. This result should be interpreted with caution since it did not reach statistical significance and is based on a small number of cases. Further research is needed to estimate more precisely the risk of major congenital malformations at high doses of ICS.

However, it is worth noting that women who took average doses of ICS were found to be less likely to have a baby with a congenital malformation. Two untested hypotheses can be put forward to explain this result. First, we might hypothesise that women taking recommended doses of ICS during the first trimester are more likely to have healthier life styles and have a lower baseline risk of having a baby with a congenital malformation. Despite adjustment at the second stage of sampling for smoking and other life style habits, residual confounding may be present. Another hypothesis is that women taking moderate recommended doses had more controlled asthma during pregnancy. Although uncontrolled asthma has been associated with adverse perinatal outcomes in several studies, ${ }^{37}$ very little evidence exists on the association between asthma (and more precisely asthma control) during pregnancy and the risk of congenital malformation in the fetus. ${ }^{35}$ These two hypotheses need further examination before we can make any conclusion.

Our study also showed that several maternal characteristics were associated with the risk of congenital malformations. As expected, we found that mothers having epilepsy and a thyroid disorder were more likely to have a baby with a congenital malformation. ${ }^{38}$ As reported in a few studies in the literature, we also found a strong inverse association between the level of education and the risk of congenital malformations, and a modest association between the area of residence and the risk of congenital malformations, mothers living in an urban area being more at risk. ${ }^{23}{ }^{39-41}$ Moreover, we found that women taking longacting inhaled $\beta_{2}$-agonists before pregancy were, at the first stage of sampling, close to three times more likely to have a baby with a malformation. This result should, however, be intrepeted with caution due to the small number of women exposed to these medications ( 48 women), and we cannot rule out the fact that this statistically significant result might reflect a type I error.

In the entire cohort we found a crude rate of congenital malformations (including major and minor malformations) of $9.2 \%$ and a crude rate of $6.1 \%$ of major malformations. This rate is high compared with the rate of $3.8 \%$ found in the study by Kallen, but is closer to the one found in the study by Schatz who found a rate of $5.4 \%$ of major congenital malformations among women who used inhaled or intranasal corticosteroids during pregnancy and in the study by Demissie who found a rate of $6.4 \%$ among women with asthma. ${ }^{8935}$ Our higher rate of congenital malformation might be explained by the large number of women with a low socioeconomic status, a low level of education and living in an urban area in our cohort. ${ }^{23} 39-41$
Our study has several strengths. First, our sample size was large with 4561 pregnancies, 1821 of which were exposed to ICS during the first trimester. Second, measurement of ICS and other medications taken during pregnancy was based on the prospective recording of filled prescriptions in the RAMQ database and could not have been influenced by the outcome of the pregnancy. Recall bias, which is a well-recognised problem in the field of congenital malformations, was avoided. Third, we were able to categorise the dose of ICS taken during pregnancy according to the doses recommended in the Canadian Asthma Consensus Guidelines and estimate the risk of congenital malformations for each of them. Fourth, the use of a two-stage sampling design allowed us to have access to important confounding variables-for example, maternal life style habits and history of congenital malformations through access to the medical chart of the mother. Fifth, we were able to control in the analysis for several potential confounding variables including markers of asthma control and severity before and during pregnancy, the use of medications during pregnancy for maternal chronic conditions other than asthma, sociodemographic characteristics of the mother, life style habits of the mother such as cigarette smoking and intake of multivitamins, as well as the family history of congenital malformations.

Our study also has weaknesses that should be taken into account in the interpretation of the results. First, exposure to medication during pregnancy was based on filled prescriptions and might not represent exactly the real intake of medications. If present, this misclassification of the exposure would tend to underestimate the ICS/malformation association. Second, the diagnoses of congenital malformation were based on data recorded in the administrative databases and were not confirmed by a dysmorphologist, nor was it confirmed within the baby's medical chart. However, there is no reason to believe that outcome misclassification, if present, would be associated with ICS exposure. In addition, since the crude rate of congenital malformations is rather large in the cohort, it is unlikely that we missed cases. Third, our cohort is mainly formed of women of low socioeconomic status and the association found in this study might not be generalised to women who have a higher socioeconomic status. Fourth, because of the nature of our observational study, we cannot completely rule out the possibility of an unmeasured confounding variable that would distort the true association between ICS intake during pregnancy and the risk of congenital malformations. As previously discussed, we may argue that women who take recommended doses of ICS during pregnancy are more health conscious and have healthier life style habits that might reduce their risk of having a baby with a congenital malformation, independent of their use of asthma medications. If present, this bias would have overestimated the beneficial effect of ICS on the risk of congenital malformations. However, this bias was lowered by adjusting the OR for ICS exposure for cigarette smoking, alcohol and illicit drug use.

In summary, the results of this study provide scientific evidence on the safety of ICS treatment during the first trimester of pregnancy with regard to minor and major congenital malformations for all doses under study, except for high doses in association with major malformations. The results of this study confirm the recommendation made by the guidelines on the treatment of asthma during pregnancy as to the use of ICS to maintain asthma under control and reduce the risk of adverse perinatal outcomes. Further studies are needed to estimate more precisely the risk of major congenital malformations associated with the use of high doses of ICS during the first trimester of pregnancy. 


\section{ACKNOWLEDGEMENTS}

We thank Ms Danielle Labrie-Pelletier from the RAMQ, Ms Louise Légaré from MED-ECHO and Ms Chantal Girard from the ISQ for their assistance with the data. We also thank Ms Cindy Odar and Ms Sylvie Daigle for reviewing the medical charts, and Dr Anne Marie Laberge from St-Justine Hospital for reviewing the list of congenital malformations.

\section{Authors' affiliations}

Lucie Blais, Université de Montréal, Montréal, Québec, Canada Marie-France Beauchesne, Jean-Luc Malo, Amélie Forget, Hôpital du Sacré-Cœur de Montréal, Montréal, Québec, Canada

Lucie Blais, Marie-France Beauchesne, Endowment Pharmaceutical Chair AstraZeneca in Respiratory Health

Évelyne Rey, Hôpital Ste-Justine, Montréal, Québec, Canada

Funding: $L B$ is the recipient of a new investigator salary support grant from the Canadian Institutes for Health Research (CIHR). This study was funded through grants received from the Fonds de la recherche en santé du Québec (FRSQ), the CIHR and the Canadian Foundation for Innovation. LB and $\mathrm{M}-\mathrm{FB}$ co-chair the Endowment Pharmaceutical Chair AstraZeneca in Respiratory Health.

Competing interests: None.

The corresponding author (LB) had full access to all the data in the study and had final responsibility for the decision to submit for publication. The funding for this study comes from non-profit peer reviewed organisations that had no involvement in the study design, collection of data, analysis, interpretation of data, writing of the report and decision to submit the paper for publication.

\section{REFERENCES}

Alexander S, Dodds L, Armson BA. Perinatal outcomes in women with asthma during pregnancy. Obstet Gynecol 1998;92:435-40

$2 \mathrm{~K}$ won $\mathrm{HL}$, Belanger K, Bracken MB. Asthma prevalence among pregnant and childbearing-aged women in the United States: Estimates from national health surveys. Ann Epidemiol 2003:13:317-24.

3 Olesen C, Steffensen FH, Nielsen GL, et al. Drug use in first pregnancy and lactation: a population-based survey among Danish women. The EUROMAP group. Eur J Clin Pharmacol 1999;55:139-44.

4 Working group on asthma and pregnancy. National asthma education program (NAEP) report of the working group on asthma and pregnancy: management of asthma during pregnancy. PB96-141593 (at the US Dpt of Commerce) (Report\# 93-3279 is the reference number at NIH), 1993:1-73.

5 Park-Wyllie L, Mazzotta P, Pastuszak A, et al. Birth defects after maternal exposure to corticosteroids: prospective cohort study and meta-analysis of epidemiological studies. Teratology 2000:62:385-92.

6 Carmichael SL, Shaw GM. Maternal corticosteroid use and risk of selected congenital anomalies. Am J Med Genet 1999;86:242-4.

7 Rodriguez-Pinilla E, Martinez-Frias ML. Corticosteroids during pregnancy and oral clefts: a case-control study. Teratology 1998;58:2-5.

8 Kallen B, Rydhstroem H, Aberg A. Congenital malformations after the use of inhaled budesonide in early pregnancy. Obstet Gynecol 1999;93:392-5.

9 Schatz M, Zeiger RS, Harden K, et al. The safety of asthma and allergy medications during pregnancy. J Allergy Clin Immunol 1997;100:301-6.

10 Greenberger PA, Patterson R. Beclomethasone diproprionate for severe asthma during pregnancy. Ann Intern Med 1983;98:478-80.

11 Schatz M, Dombrowski MP, Wise R, et al. The relationship of asthma medication use to perinatal outcomes. J Allergy Clinic Immunol 2004;113:1040-5.

12 Silverman M, Sheffer A, Diaz PV, et al. Outcome of pregnancy in a randomized controlled study of patients with asthma exposed to budesonide. Ann Allergy Asthma Immunol 2005;95:566-70.

13 Régie de I'assurance maladie du Québec. Statistiques annuelles. Québec, Oct, 1997.
14 Martel MJ, Rey É, Beauchesne M-F, et al. Use of inhaled corticosteroids during pregnancy and risk of pregnancy induced hypertension: nested case-control study. BMJ 2005;330:230-3.

15 Blais L, Beauchesne MF. Use of inhaled corticosteroids following discharge from an emergency department for an acute exacerbation of asthma. Thorax 2004;59:943-7.

16 Tamblyn R, Lavoie G, Petrella L, et al. The use of prescription claims databases in pharmacoepidemiological research: the accuracy and comprehensiveness of the prescription claims database in Québec. J Clin Epidemiol 1995;48:999-1009.

17 Levy AR, Mayo NE, Grimard G. Rates of transcervical and pertrochanteric hip fractures in the province of Quebec, Canada, 1981-1992. Am J Epidemiol 1995; 142:428-36

18 Blais L, Lemière C, Berbiche D. Validation of asthma diagnostic codes in the administrative health databases of Québec, Canada. Pharmacoepidemiol drug saf 2004;13:S32.

19 Collet JP, Schaubel D, Hanley J, et al. Controlling confounding when studying large pharmacoepidemiologic databases: a case study of the two-stage sampling design. Epidemiology 1998;9:309-15

20 Schaubel D, Hanley J, Collet JP, et al. Two-stage sampling for etiologic studies. Sample size and power. Am J Epidemiol 1997; 146:450-8

21 Heinonen OP, Slone D, Shapiro S. Birth defects and drugs in pregnancy. Littleton: Publishing Sciences Group, 1977.

22 Boulet LP, Becker A, Berube D, et al. Canadian Asthma Consensus Report, 1999 Canadian Asthma Consensus Group. CMAJ 1999;161:S1-61.

23 Koren G, Pastuszak A, Ito S. Drug therapy - Drugs in pregnancy. N Engl J Med 1998;338:1128-37.

24 Zeger SL, Liang KY, Albert PS. Models for Longitudinal Data - A Generalized Estimating Equation Approach. Biometrics 1988;44:1049-60.

25 Greenland S. Modeling and variable selection in epidemiologic analysis. Am J Pub Hlth 1989:79:340-9.

26 Jana N, Vasishta K, Saha SC, et al. Effect of bronchial asthma on the course of pregnancy, labour and perinatal outcome. J Obstet Gynaecol 1995;21:227-32.

27 Fitzsimons R, Greenberger PA, Patterson R. Outcome of pregnancy in women requiring corticosteroids for severe asthma. J Allergy Clin Immunol 1986;78:349-53

28 Schatz $M$. Interrelationships between asthma and pregnancy: a literature review. J Allergy Clin Immunol 1999;103:S330-S336.

29 Schatz M, Zeiger RS, Hoffman CP. Intrauterine growth is related to gestational pulmonary function in pregnant asthmatic women. Kaiser-Permanente Asthma and Pregnancy Study Group. Chest 1990;98:389-92.

30 NAEPP Expert Panel Report. Managing Asthma During Pregnancy: Recommendations for Pharmacologic Treatment-2004 Update. J Allergy Clinic Immunol 2005; 115:34-46.

31 Cousins L. Fetal oxygenation, assessment of fetal well-being, and obstetric management of the pregnant patient with asthma. J Allergy Clin Immunol 1999; 103:S343-9

32 Guy ES, Kirumaki A, Hanania NA. Acute asthma in pregnancy. Crit Care Clin 2004;20:731-45.

33 SteniusAarniala BSM, Hedman J, Teramo KA. Acute asthma during pregnancy. Thorax 1996:51:411-14.

34 Braems G. Fetal hypoxemia on a molecular level: adaptive changes in the hypothalamic-pituitary-adrenal (HPA) axis and the lungs. Eur J Obstet Gynecol Reprod Biol 2003;110:S63-9.

35 Demissie K, Breckenridge MB, Rhoads GG. Infant and maternal outcomes in the pregnancies of asthmatic women. Am J Respir Crit Care Med 1998;158:1091-5.

36 Bahna SL, Bjerkedal T. The course and outcome of pregnancy in women with bronchial asthma. Acta allergol 1972;27:397-406.

37 Murphy VE, Clifton VL, Gibson PG. Asthma exacerbations during pregnancy: incidence and association with adverse pregnancy outcomes. Thorax 2006;61:169-76.

38 Cunningham F, MacDonald P, Gant N, et al. Williams Obstetrics. Stamford: Appleton \& Lange, 1997.

39 Blanco MJ, Lacasana M, Borja A, et al. Socioeconomic factors and the risk of anencephaly in a Mexican population: a case-control study. Public Health Rep 2005; 120:39-45.

40 Seegmiller RE, Hansen WN. Congenital malformations in Utah. Teratology 1980;22:187-99.

41 Vrijheid M, Dolk H, Stone D, et al. Socioeconomic inequalities in risk of congenital anomaly. Arch Dis Child 2000;82:349-52. 